\title{
Sistematização de estratégias de ensinar-aprender pesquisa na graduaçãa
}

\author{
Zuleica Maria Patrício \\ Maria Regina Silvério ${ }^{2}$ \\ Ivete Maria Ribeiro ${ }^{3}$ \\ Janete Elza Felisbino ${ }^{4}$ \\ Ingrid May Brodbeck \\ Greice Wessler Medeiros Martins ${ }^{6}$ \\ Gilmara Medeiros Vieira da Silva \\ Adriana Elias dos Reis ${ }^{8}$
}

PATRÍCIO, Z.M. et al. Systematization of strategies for teaching-learning research in an undergraduate course. Interface - Comunic., Saude, Educ., v.15, n.39, p.1159-72, out./dez. 2011.
This study aimed to analyze the systematization of pedagogical practices related to the teaching and learning of research methods in the daily routine of the disciplines of a health undergraduate course. The data were obtained from documents referring to developed pedagogical activities and analyzed through a content analysis technique, following the categories of the adopted social practices systematization framework, namely: object delimitation; time and context; objectives and purposes; employed frameworks; content of the utilized practices and strategies; dynamics of the activities and generated feelings; results; conclusions and proposals for further activities. The results present a teaching-learning research method, collectively created, that has its own theoretical-methodological framework. This framework guides, throughout all the disciplines, the development of strategies to build knowledge on an increasing complexity level, based on problematic health situations and on qualitative and quantitative data arising from different sources and socio-environmental contexts.

Keywords: Research teaching. Higher Education. Teaching-learning strategies. Systematization of practices.
O objetivo deste trabalho foi analisar a sistematização de práticas pedagógicas de ensinar-aprender pesquisa no cotidiano das disciplinas de um curso de graduação da área da saúde. Os dados foram levantados em documentos referentes a atividades pedagógicas desenvolvidas e analisados pela técnica de análise de conteúdo seguindo categorias do referencial de sistematização de práticas sociais adotado: delimitação do objeto; tempo e contexto; objetivos e finalidades; referenciais utilizados; conteúdo das práticas e estratégias utilizadas; dinâmica das atividades e sentimentos gerados; resultados; conclusões e propostas de encaminhamentos. Os resultados apresentam um método de ensinaraprender pesquisa, criado coletivamente, constituído por referencial teóricometodológico próprio que orienta, no decorrer de todas as disciplinas, o desenvolvimento de estratégias para construção de conhecimentos em nível de complexidade crescente, com base em situações-problema da saúde e dados qualitativos e quantitativos de diferentes fontes e contextos socioambientais.

Palavras-chave: Ensino da pesquisa. Educação Superior. Estratégias de ensinoaprendizagem. Sistematização de práticas.
${ }^{9}$ Participaram, também, como coautores, os seguintes docentes da Universidade do Sul de Santa Catarina: Ana Maria Henrique Martins Costa, Elvis Diene Bardini e Vera Maria Antunes da

${ }^{1}$ Docente aposentada Universidade Federal de Santa Catarina. Rua das Araras, 396, Lagoa da Conceição. Florianópolis, SC, Brasil. 88.062-075. zucamp@ccs.ufsc.br

2-8 Universidade do Sul de Santa Catarina, Campus Fonseca Pinto. 


\section{Introdução}

A intenção de integrar a pesquisa ao ensino tem sido uma constante nos discursos de representantes de universidades brasileiras e nos textos dos projetos pedagógicos de seus cursos de graduação. Prova disso é o aumento considerável de programas de incentivo à pesquisa que incluem alunos de graduação, o que se constata pelo número de relatórios de pesquisa apresentados em eventos científicos (Fórum, 2009; Moor, 2003).

Entretanto, esse cenário, se analisado com base no número de graduandos no território nacional, mostra que apenas uma minoria tem o privilégio de aprender a fazer pesquisa na graduação. Isso porque a cultura da pesquisa nesse contexto é predominantemente focada na produção de conhecimentos científicos via projetos de pesquisa. Há graduandos que, durante a vida acadêmica, têm, no Trabalho de Conclusão de Curso (TCC), sua única oportunidade de aprender a pesquisar.

Inúmeros trabalhos sobre essa temática mostram tentativas de incrementar a pesquisa na graduação e suas conquistas e dificuldades. Entretanto, observa-se que poucos tratam de práticas sistemáticas de pesquisa no decorrer do cotidiano das disciplinas que compõem o currículo do curso (Laffin, 2008; Rossi, Ribeiro, Teodósio, 2008; Soubhia, Garanhani, Dessunti, 2007; Nóbrega-Therrien, Therrien, 2006).

A análise de relatórios de vários projetos pedagógicos de cursos de graduação em Santa Catarina valida essa observação e aponta que o desafio ainda é integrar atividades acadêmicas de ensino, pesquisa e extensão.

O estudo de Comerlatto (2008), realizado em um curso de graduação, demonstrou que o ensino da pesquisa está concentrado em disciplinas específicas, e que a concretização da transversalidade da pesquisa é um desafio a ser enfrentado. A autora sustenta que a importância da pesquisa na formação profissional reporta para a necessidade de se repensarem modos de ensinar geradores de processos educativos interdisciplinares, que assegurem o envolvimento com a pesquisa e para a pesquisa.

O trabalho de Morato (2005), com base em Marques (1997), Ruiz (1992) e Lucas (1991), destaca a importância do ensino da pesquisa para que o aluno desenvolva o senso de busca e a disciplina de trabalho, de forma a habilitá-lo para seguir ou reconstituir trajetórias metodológicas percorridas por cientistas. Nesta perspectiva, a pesquisa tem um significado de redescoberta e deixa de ser vista como cristalizadora de conhecimentos armazenados, mas como reconstrutora da ciência.

Desde muito tempo é denunciada a preponderância do ensino fragmentado subsidiado por reproduções de textos, fichas e apostilas, às vezes ultrapassadas e descontextualizadas, e focado na memorização de conteúdos aplicados de forma acrítica (Demo, 2006; Botomé, 1996).

Paulo Freire, incansável defensor de práticas educacionais de natureza participante e de caráter ético e estético, assinala a importância de a pesquisa estar obrigatoriamente inserida no cotidiano dessas práticas (2000).

O estudo de Zatti (2007) contribui para elucidar essa problemática e também aponta perspectivas de superação. Para além da aprendizagem de conteúdos, o autor, com base em Freire e Kant, mostra a importância da prática pedagógica que possibilita desenvolver a autonomia do aluno para a busca intencional e a percepção ética do conhecimento, além de promover a sua inserção de forma cidadã nas questões sociais.

A constatação de que o aluno deseja participar de processos pedagógicos em que possa encontrar pessoas que, junto com ele, procurem o novo, é um dos aspectos dessa realidade (D'Ambrósio, 1997).

O ideal seriam processos pedagógicos que promovessem situações de aprendizagem de forma reativa e que resultassem em crescimento pessoal e aquisição de conhecimentos originais e autênticos, na medida em que toda educação supõe uma intervenção sobre a vitalidade do ser humano que se educa (Droguett, 2002).

Em contextos educacionais que envolvam cursos de graduação inseridos nas grandes áreas das Ciências Humanas, Ciências da Saúde e Ciências Sociais Aplicadas, a importância de sistematizar o conhecimento no decorrer do curso parece ser ainda maior. Conforme Ávila (1995), sendo a universidade um espaço de laboratório da sociedade, é de se esperar que suas atividades cotidianas de ensino, por si só, contribuam para melhorar as práticas pedagógicas e a atenção às demandas da população. 
A questão é que incrementar a pesquisa na graduação de maneira ampliada, e ainda considerar a unidade ser humano, profissional e cidadão, exige outras estratégias além daquelas do TCC e de projetos de pesquisa isolados.

Isso requer aperfeiçoar práticas pedagógicas que possibilitem tornar processos cotidianos de ensinoaprendizagem espaços de maior geração de conhecimentos e menos de reprodução, de maneira que professores e alunos, instrumentalizados com ferramentas de pesquisa, desenvolvam os conteúdos que precisam ensinar e aprender integrados ao contexto da vida e da profissão.

Com base nessa problemática, pressupõe-se que incrementar estratégias de pesquisa no cotidiano das práticas pedagógicas do ensino de graduação torna mais acessível a aprendizagem da pesquisa e eleva a qualidade do ensino e o caráter da universidade, haja vista discussões mais contemporâneas sobre seu papel na sociedade, em especial aquelas incitadas por Santos (2005).

Partindo de concepções dessa natureza e com o intuito de operacionalizar o Projeto Pedagógico do Curso (PPC) de graduação em Enfermagem de uma universidade de Santa Catarina, um grupo de professores desse curso criou o Projeto "Estratégias de Ensinar-Aprender Pesquisa na Graduação".

A iniciativa gerou o desenvolvimento de um conjunto de atividades pedagógicas voltado à inserção da pesquisa em todos os semestres do curso, com base na integração dos conteúdos das disciplinas.

Ao final da experiência, os participantes - professores e alunos - demonstraram interesse em conhecer o conjunto das atividades realizadas nos diversos semestres, para fins de avaliação e aperfeiçoamento do trabalho.

Essa expectativa desencadeou uma pesquisa de abordagem qualitativa, com o objetivo de analisar o processo de implantação dessa modalidade de ensino, desenvolvido no contexto do curso em 2008.

$\mathrm{Na}$ fase exploratória, o levantamento dos registros relacionados ao cotidiano e às avaliações das atividades mostrou uma complexidade de situações sociais no âmbito da universidade e fora desta, envolvendo a população e outros profissionais.

Essa análise inicial dos dados criou, nos pesquisadores, a necessidade de busca de um caminho metodológico próprio para orientar a análise de todo o processo, em sintonia com o PPC e com as referidas expectativas dos participantes. Decidiram, então, focar a pesquisa na sistematização das práticas pedagógicas realizadas.

Com essa metodologia de pesquisa, o trabalho pedagógico foi identificado como um método, ainda em aperfeiçoamento, representado por estratégias de ensinar pesquisa e conteúdos temáticos, fazendo pesquisa no decorrer das disciplinas, cuja proposta poderia ser adaptada para aplicação em outros contextos acadêmicos.

\section{Metodologia}

Caracteriza-se como pesquisa de abordagem qualitativa do tipo estudo documental. Essa modalidade se fundamenta na apreciação de documentos, de fonte primária ou secundária.

A fonte dos dados foi o conjunto dos documentos originais produzidos por alunos e docentes no decorrer das atividades pedagógicas. Foram analisados todos os registros das atividades integradas de pesquisa realizadas nos semestres do curso, a saber: atas de reuniões entre alunos e docentes e entre docentes; diário das observações participantes, realizadas pelos docentes durante as atividades pedagógicas; e avaliações da disciplina.

Os dados foram analisados pela técnica de análise de conteúdo, conforme Minayo (2004) e Bardin (1977), e com foco na sistematização das práticas segundo um referencial próprio. Utilizou-se, como guia, um conjunto de categorias desenvolvidas por Botero (2001), Ghiso (2001), Jara (1996) e Barnechea, González, Morgan (1994).

Adotando-se esse referencial para a comunidade acadêmica, a partir de Ghiso (2001), utiliza-se o sentido de sistematização como um processo de recuperação, tematização e apropriação de uma determinada prática. Relacionar, sistêmica e historicamente, seus componentes teórico-práticos possibilita compreender e explicar os contextos, fundamentos e sentidos, as lógicas e os aspectos problemáticos que se apresentam com a experiência, e, também, transformar e qualificar propostas educativas. 
A sistematização assume um caráter de resgate da experiência de uma prática, da produção de conhecimentos e do empoderamento dos sujeitos sociais envolvidos na prática, e, ao mesmo tempo, constitui-se, por si só, como investigação social (Ghiso, 2001).

Jara (1996) fortalece essa concepção ao afirmar que a sistematização contribui para: obter-se compreensão mais profunda das experiências que se realizam, com o fim de melhorá-las; compartilhar com outras práticas similares os ensinamentos que emergiram durante a experiência; suscitar reflexões teóricas sobre as temáticas envolvidas, incitando à construção de teorias e, também, de conhecimentos aplicados que surgem com as práticas sociais concretas.

Esses referenciais estão em sintonia com as diretrizes que orientam o Projeto Pedagógico do curso em estudo e as Políticas Públicas de Educação e de Saúde, e atendem à expectativa de que práticas pedagógicas possam fortalecer o ideal da abordagem "prática social transformadora".

Nessa conformação, a sistematização do processo de ensinar pesquisa e conteúdos temáticos, fazendo pesquisa no decorrer das disciplinas, contempla as categorias orientadas por Ghiso (2001) e Barnechea, González e Morgan (1994), a saber: delimitação do objeto; tempo e contexto; objetivos e finalidades (intenções); referenciais utilizados; conteúdo das práticas, incluindo aspectos sobre etapas do processo, dinâmica das atividades, estratégias utilizadas e sentimentos gerados; resultados apontando mudanças na situação objeto do estudo e nos sujeitos participantes e em suas relações; conclusões e propostas de encaminhamentos; e a elaboração de um documento escrito.

Os princípios éticos aplicados no estudo foram os seguintes: autorização da coordenação do curso e dos docentes para consulta dos registros; aprovação coletiva para a publicação em reunião de colegiado; manutenção do anonimato na descrição; e respeito à coautoria de todos os professores participantes, representados pelos respectivos coordenadores do processo pedagógico de cada semestre do curso. Cópia escrita do documento final foi enviada à Reitoria e à Coordenação do curso.

As limitações identificadas na pesquisa foram decorrentes de algumas dificuldades para se encontrarem as categorias definidas, tendo em vista diferenças na qualidade dos registros elaborados pelos participantes.

\section{Apresentação e discussão dos resultados}

A descrição e a discussão das atividades integradas de pesquisa são apresentadas conforme as categorias de análise referidas.

\section{Objeto, contextualização, objetivos, finalidades (intenções) e referencial teórico-metodológico}

Em fevereiro de 2008, surgiu a oportunidade de se fomentar o Projeto Estratégias de EnsinarAprender Pesquisa na Graduação. Nasceu de uma demanda dos professores do terceiro semestre do curso, interessados em implementar a pesquisa no contexto da Atividade Integrada, identificada como um espaço de ensino de caráter obrigatório em todos os semestres, cujo objetivo é integrar as temáticas do ementário de cada semestre.

O grupo trouxe, à professora que desempenhava o papel de assessora em pesquisa, uma proposta para a Disciplina daquele semestre. Era um projeto de pesquisa que havia sido elaborado para que os alunos o desenvolvessem com a coordenação dos professores. A análise crítica da proposta evidenciou algumas limitações relativas às condições docentes e discentes, bem como ao tempo insuficiente no semestre para a sua realização.

Decidiu-se, no coletivo, por outra modalidade de trabalho: alunos e docentes aplicariam estratégias de ensinar-aprender pesquisa para desenvolver, de maneira integrada, os conteúdos das disciplinas daquele semestre. Estava nascendo a Atividade Integrada de Pesquisa (AIP).

No segundo semestre de 2008, com base em avaliação participativa desse trabalho, a AIP foi validada e aperfeiçoada para os demais semestres, passando a ser desenvolvida por todos os professores e alunos. 
Na perspectiva da interdisciplinaridade e participação efetiva, o primeiro desafio na implantação da proposta foi integrar os demais professores no processo, especialmente aqueles não-enfermeiros, que tinham carga horária reduzida nesse curso e atuavam em outros cursos.

Em colegiado, ficou estabelecido como objetivo geral da AIP: desenvolver processos de ensinaraprender de caráter interdisciplinar e participante, que estimulem a produção do conhecimento pelo aluno, por princípios e técnicas de pesquisa, em nível de complexidade crescente, no decorrer das disciplinas do curso. E, como objetivos específicos: a) estudar sobre temáticas relacionadas às disciplinas do curso com base na criação, no desenvolvimento e na aplicação e avaliação de estratégias de pesquisa, no âmbito de fontes bibliográficas, bancos de dados e de diversos contextos sociais, com a população e outros profissionais; b) desenvolver atividades de pesquisa, tendo como referência as diretrizes curriculares que compõem o PPC, suas linhas de pesquisa e temáticas transversais.

Particularmente, no contexto do curso, as disciplinas visam o desenvolvimento do potencial dos alunos para identificarem necessidades humanas de saúde em todo o ciclo vital e em seus diversos ambientes, com vistas a criarem, manterem, aperfeiçoarem ou reprogramarem ações e processos de cuidar da vida na perspectiva da promoção da saúde e da prevenção, do tratamento e da reabilitação de problemas de saúde individuais e coletivos, considerando a unidade das dimensões biológica, socioambiental, cultural e psicoespiritual.

Identificou-se, em todo o processo, a aplicação de várias diretrizes, prescritas no PCC, relacionadas ao arcabouço técnico-humanístico próprio da profissão: abordagem interdisciplinar e intersetorial; ações participantes envolvendo gestores de serviços públicos e privados, indivíduos, famílias, comunidades e a sociedade de forma geral; consideração às diversidades culturais, ambientais e afetivas relacionadas às situações identificadas; promoção de consciência crítica construtiva; e aplicação da ética profissional.

A análise dos dados mostra que a estratégia de construir conhecimentos através de atividades de pesquisa científica no decorrer das disciplinas segue um conjunto de referenciais teóricos e metodológicos que se complementam e que dizem respeito ao contexto da saúde de forma geral - em especial, à Enfermagem, no que se refere ao seu arcabouço teórico e metodológico voltado ao cuidado direto e indireto, e à Saúde Coletiva, à Biologia, à Medicina, à Sociologia, à Nutrição, à Psicologia, à Filosofia e à Educação.

Assim, são adotados vários autores temáticos e da metodologia da pesquisa, conforme especificidades da situação/objeto de estudo no semestre, além das particularidades relacionadas ao curso, em que se preveem, desde o segundo semestre, a aplicação e o aprimoramento de referenciais teórico-metodológicos criados na Enfermagem com foco na essência desta profissão: o Cuidado Humano Integral ao indivíduo, a grupos, à família e à comunidade (Patrício, 1995; Colliére, 1986; Leininger, 1984; Horta, 1979).

No âmbito da Educação, os referenciais adotados estão em sintonia com ideias de Paulo Freire (2000, 1983), D'Ambrósio (1997) e Grossi (1995), cuja essência é focada na construção do ser integral, indivíduo e coletivo, cidadão local, universal e livre, para participar e criar mediante atitudes éticas e estéticas de convivência solidária.

Sustentada por essa concepção e na especificidade da profissão e do PPC, a AIP, neste contexto, considera a estratégia cuidar-pesquisando, ou pesquisar-cuidando. A expectativa é tornar o próprio processo de trabalho um espaço educativo, terapêutico e revitalizador do conhecimento e da pessoa, de maneira que seus resultados sejam satisfatórios para os participantes, para o ambiente e para a profissão (Patrício et al., 2004; Patrício, 2000, 1994, 1990).

A análise dos processos e produtos das práticas desenvolvidas mostra que as finalidades da AIP vão além do incentivo à cultura da pesquisa no cotidiano das práticas pedagógicas do curso. Há, também, a expectativa de contribuir para incrementar projetos de extensão, como espaços de pesquisa participante ou pesquisa ação, e incentivar a integração docente-docente, docente-discente e discente-discente, por estratégias participantes de produção de conhecimentos.

Particularmente, pelo contexto profissional onde foi gerado, o processo objetiva desenvolver estratégias para a produção de conhecimentos básicos e aplicados acerca do fenômeno saúde-adoecer humano, atualizados e contextualizados na realidade da Região e do Brasil, de maneira a subsidiar a identificação, a criação e o aperfeiçoamento de referenciais teórico-metodológicos voltados ao cuidado 
integral da saúde do ser humano em todo o seu ciclo vital e nas diversas situações da vida, incluindo seu processo de morrer.

Para tanto, o perfil de saúde, o potencial e a diversidade socioambiental, as tecnologias à disposição, o conjunto das políticas públicas e as tendências do mercado de trabalho são considerados no aprimoramento da competência técnico-científica e humanística da profissão, com vistas a atender expectativas e necessidades de saúde da sociedade.

A análise do conjunto dos referenciais e princípios adotados na AIP, bem como de suas finalidades, indica que o processo pedagógico destina-se a estimular o empoderamento pessoal e profissional do aluno com base na integração de proposições éticas e estéticas e componentes teóricos e metodológicos de caráter participante, construtivista, interdisciplinar, dialético e solidário.

\section{Descrição das práticas e estratégias desenvolvidas}

O processo da AIP se realiza no decorrer das disciplinas, mediante atividades de ensinar pesquisa fazendo pesquisa. Em cada semestre do curso, com exceção do último, os professores elegem um tema que atenda à proposta de integrar os conteúdos e os professores das disciplinas, bem como definem a operacionalização da aprendizagem do aluno, respeitando o nível de complexidade esperado no semestre e a produção do conhecimento fundamentada em movimentos individuais e coletivos de cunho sistematizado, responsável e prazeroso.

O elemento motivador é o tema - ou situação-problema -, transformado em pergunta de pesquisa e definido com base na análise dos conteúdos das disciplinas, na sua importância no cenário atual e na sua pertinência frente: aos objetivos, aos princípios, às finalidades e aos elementos teóricos e metodológicos estabelecidos para orientar a AIP.

As temáticas transversais do PPC são integradas ao processo da pesquisa, conforme a profundidade exigida no semestre: ética, interdisciplinaridade, administração, cidadania, políticas públicas e práticas naturais em saúde.

Em cada semestre, a AIP tem seu Plano de Ensino, composto pelos seguintes itens: a) Objetivos (aqueles apresentados anteriormente); b) Objetivos Específicos, relacionados às disciplinas do semestre e ao grau de complexidade exigido para aprender a responder às questões definidas para aquele momento acadêmico; c) Atividade Proposta, com seus itens e desmembramentos; d) Método de Ensino-Aprendizagem; e) Cronograma; f) Bibliografia. Com exceção dos itens a e b, os demais podem ser alterados no semestre seguinte, em razão da diversidade e pertinência de questões de pesquisa para o momento.

No primeiro semestre do curso, a AIP tem a responsabilidade de inserir o aluno no movimento participante de conhecer temas relacionados às disciplinas e à profissão por meio da pesquisa. $O$ objetivo, nesse momento acadêmico, é desenvolver atividades que estimulem o potencial do aluno para: aprender a conhecer bancos de dados da área; aplicar normas da metodologia científica; identificar publicações científicas na área; ler essas obras; elaborar perguntas de pesquisa com base no contexto atual, e responder a elas via artigos científicos e livros didáticos indicados; e para apresentar os resultados de forma escrita e em discussão de grupo, conforme modelos de trabalhos acadêmicos.

Do segundo ao sexto semestre do curso, o aluno vai, gradativamente, aprendendo sobre: princípios éticos e estéticos da pesquisa; rigor metodológico; diversidade de fontes de dados; e técnicas de pesquisa de abordagem quantitativa e qualitativa - levantamento, registro e análise de dados e devolução de resultados - incluindo adaptação e elaboração de instrumentos, conforme o objeto da pesquisa.

Nesse processo, ele aprende a elaborar caminhos que levam a conhecimentos, e descobre e aperfeiçoa temas relacionados às disciplinas do semestre. Por exemplo, no contexto analisado, os temas desenvolvidos do segundo ao sexto semestres do curso foram os seguintes, respectivamente: "A ocorrência de doenças infectocontagiosas que compõem a lista de notificação compulsória na região sul de Santa Catarina"; " Identificação dos portadores de diabetes mellitus cadastrados em uma unidade do Programa Saúde da Família do Município"; "Situações de estresse vivenciadas por acadêmicos do curso de enfermagem de uma universidade de Santa Catarina e possibilidades de prevenção de ocorrências e 
agravos"; " Cuidados acerca da hipertensão: percepção dos usuários atendidos em um hospital geral, unidades básicas de saúde e ambulatório-escola da universidade"; "O Processo de Enfermagem: percepção dos enfermeiros sobre a sua aplicação no cotidiano das práticas profissionais".

No sétimo semestre, como as atividades são concentradas em dois contextos de saúde - hospitalar e saúde pública - as temáticas definidas foram: "Qualidade da assistência de enfermagem no âmbito hospitalar" e "Qualidade da assistência de enfermagem na saúde coletiva".

No oitavo semestre, para integrar todas as disciplinas e aperfeiçoar as temáticas transversais do PPC, o aluno aplica seus conhecimentos na elaboração de sua própria pesquisa no TCC, conforme as linhas de pesquisa do curso, e participa da promoção de um Seminário de Controvérsias acerca de questões éticas originadas de suas atividades práticas.

A consolidação da proposta de cada semestre se dá pela participação solidária entre alunos e professores no processo de responder à situação-problema estabelecida, mediante a busca de informações atualizadas em banco de dados credenciados e artigos e livros recomendados.

Conforme o objetivo específico do semestre e o grau de complexidade, o professor orienta sobre como buscar dados em fontes socioambientais primárias, ou seja, nos contextos onde os fenômenos ocorrem. Inclui-se, aqui, a elaboração e a aplicação do Termo de Consentimento Livre e Esclarecido.

Por exemplo, na AIP do terceiro semestre, ficou determinado que o aluno, além de aperfeiçoar os conteúdos teóricos e as ferramentas aprendidas nos semestres anteriores - como buscar dados na literatura e em bancos de dados oficiais e elaborar registros de forma sistematizada - precisa aprender a entrar em campo de natureza mais complexa, com atitude de pesquisador social, e a produzir um banco de dados.

Esse é o momento de o aluno responder a uma pergunta de pesquisa com informações identificadas em registros de atendimentos de usuários de um serviço de saúde pública. É sua primeira experiência com dados em documentos originais.

Nessa fase, o aluno começa o seu aprendizado prático sobre aspectos éticos relacionados ao como entrar e sair de uma instituição e ao como tratar informações sigilosas, e, também, sobre instrumentos específicos para desenvolver a atividade.

Para tanto, ele aprende: a solicitar autorização oficial por escrito para estar no ambiente de trabalho da equipe de saúde; a identificar documentos que registram o atendimento prestado à população, e a comprometer-se a devolver os resultados para a instituição.

Aprende, também, a: elaborar o formulário de coleta de dados; ler e analisar registros dos profissionais da saúde; identificar os dados que responderão à pergunta da pesquisa; registrar e organizar os dados de maneira sistematizada; criar um banco de dados em planilha específica; e a elaborar a apresentação em gráficos e criar formas de devolução de resultados para a instituição. E, finalmente, aprende a discutir, com seus pares e professores, sobre os resultados, focando aspectos metodológicos e conteúdos específicos, bem como aprende a refletir criticamente sobre a realidade encontrada com base na literatura clássica e contemporânea, nas políticas públicas e nos princípios éticos inerentes à profissão.

Foi identificado, também, que o terceiro semestre possibilita, ao aluno, perceber a qualidade da recepção dada aos cidadãos nos serviços de saúde e a importância dos resultados da pesquisa para o aperfeiçoamento de programas e ações de atenção à saúde da população.

A análise reflexiva dos resultados dessa AIP despertou a consciência dos professores para outros âmbitos, como a necessidade de se introduzirem temas no início do curso, por exemplo, o "acolhimento", e a validação do potencial dos bancos de dados que a AIP produz, para subsidiar outros estudos de abordagem qualitativa e quantitativa, e decisões de gestores de saúde do Município.

A análise do conjunto das AIP fez também emergir categorias que ampliaram o construto dessa estratégia, como: "papel do professor"; "papel do coordenador do semestre"; e "papel do coordenador do curso".

O papel do professor é de mediador no processo de construção do conhecimento e, também, de aprendiz: orienta o trabalho em grupo respeitando o nível de compreensão dos alunos naquele momento do curso; reforça experiências anteriores; apresenta as ferramentas necessárias para a produção do conhecimento condizente com o grau de complexidade para aquele momento acadêmico; discute sobre a situação-problema escolhida; atende os alunos em suas dificuldades, para que possam 
avançar nas etapas com satisfação; estimula a sua criatividade durante o processo; orienta a integração dos dados; participa de decisões do grupo sobre propostas de socialização dos resultados e de apresentação pública do trabalho final.

O professor busca ser participante ativo do processo interdisciplinar e solidário com colegas, alunos e coordenação de curso, em parceria com profissionais e população envolvidos nas atividades, e, ainda, incorpora o papel de sujeito que, enquanto ensina, também se aperfeiçoa.

No decorrer da AIP, o professor é estimulado, também, a criar estratégias que possibilitem ao aluno aumentar seu potencial de participação. Há mobilização de energias para aprendizagem de atitudes relacionadas à interação social de cunho humanístico e à disciplina de trabalho individual e coletivo, como: organização do tempo no dia e na semana; estabelecimento de prioridades no cronograma do semestre; liberdade de expressão; responsabilidade; criatividade; trabalho solidário e respeitoso entre colegas; e diálogo e tolerância frente às diferenças pessoais.

Os dados mostram que, durante e ao final do processo, é o aluno que traz novas perguntas e reflexões para serem incorporadas aos processos de ensinar-aprender, exigindo do professor reflexões e aperfeiçoamento contínuos.

Em cada semestre, além de responsável por um grupo de alunos, um dos professores também é coordenador da AIP. Seu papel é manter a unidade de compreensão e ação entre os participantes, enquanto o do coordenador do curso é garantir condições para a implementação da AIP, como providenciar adequações curriculares, alocar carga horária para os docentes e manter a coerência das atividades com o PPC.

\section{Avaliação e encaminhamentos}

$\mathrm{Na}$ AIP/2008, foram elaborados 18 instrumentos de pesquisa; participaram do processo 264 alunos e 39 professores, além dos "sujeitos do estudo", representados por acadêmicos do curso, equipes de enfermagem e usuários de serviços de saúde ambulatoriais e hospitalares do Município.

O processo de avaliação teve caráter participativo, seguindo a rotina do curso para avaliação de disciplinas. Envolveu alunos, professores e as coordenações do curso e do projeto, e realizou-se em três momentos: no decorrer do semestre, por meio de depoimentos verbais em encontros formais e informais; na apresentação dos trabalhos finais; e em reunião de colegiado, ao final do semestre.

Concluiu-se que a avaliação da AIP como um todo, considerando-se as oito fases do curso, somente será possível quando os alunos que participaram desde o início estiverem concluindo o curso.

Entretanto, como avaliação de processo, pôde-se evidenciar a viabilidade da estratégia, tendo em vista o alcance dos objetivos propostos junto aos alunos e a sinalização positiva para as finalidades esperadas.

A análise dos dados referentes a essa avaliação mostra três categorias: "conquistas", "dificuldades" e "sugestões/encaminhamentos". As conquistas foram semelhantes para todos, variando em intensidade conforme particularidades pessoais e grupais: maior integração docente-docente e docentediscente; motivação de docentes e discentes para realização de estudos, pesquisas e publicação de artigos científicos; aplicação da linguagem de pesquisa no cotidiano; descoberta e incremento do uso de diferentes bancos de dados e de bibliografias de caráter científico no preparo das aulas e dos trabalhos acadêmicos; aperfeiçoamento teórico-metodológico; e estímulo à criatividade discente e docente para o desenvolvimento de estratégias de ensino, pesquisa e socialização dos dados.

Em especial, para o aluno, evidenciou-se que a AIP possibilita: a aproximação com o ambiente físico e o contexto social da saúde em fases iniciais; a associação concreta da teoria com a prática; ampliação de sua visão de mundo, o que proporciona maior compreensão sobre o processo saúde-adoecer da população; descobertas próprias sobre a construção da saúde, dos serviços e dos processos de cuidar; maior sensibilidade e criatividade; a apropriação de referenciais teóricos para análise de dados empíricos; e espaços de reflexão crítica que conduzem à elaboração de sínteses sobre responsabilidades e possíveis desafios inerentes ao exercício profissional.

As dificuldades identificadas no processo foram decorrentes, em especial, da ausência de carga horária docente para essa atividade e de problemas de cunho pessoal. Houve situações que provocaram estresse e desconforto em alunos e professores. Para os primeiros, a razão foi falta de tempo para os 
trabalhos coletivos. Quanto aos professores, o estresse foi maior para aqueles que necessitaram investir mais tempo para aprender o que deviam ensinar, especialmente tendo outro vínculo empregatício.

Professores acostumados a levar o conteúdo pronto para a sala de aula tiveram maior dificuldade. $\mathrm{Na}$ AIP, o professor é estimulado a não "dar aula"; sendo assim, desenvolver processos que orientam o aluno para a construção do conhecimento temático e metodológico, partindo de uma pergunta de pesquisa, exigiu revisão total das práticas pedagógicas.

Identificou-se que apontar vazios de conhecimentos, ensinar ferramentas científicas para a busca de dados, indicar as fontes desses dados, exercitar a sistematização, desenvolver processos de interação, de reflexão crítica e de elaboração de sínteses e, ainda, cobrar normas científicas e estimular a criatividade no processo, incluindo formas de apresentação dos resultados, não são tarefas fáceis para aqueles professores que assim não aprenderam.

$\mathrm{Na}$ avaliação final, as dificuldades foram percebidas como desafios a serem trabalhados com vistas ao aperfeiçoamento da proposta, posto que alunos e professores, por unanimidade, sugeriram a continuidade da AIP no curso. Dos 264 alunos, apenas 01 considerou a AIP negativa, justificando que "aprender a pesquisar não é importante para a profissão".

Um dos aspectos evidenciados diz respeito à necessidade de se incrementar um movimento de reflexão crítica entre professores e a coordenação do curso acerca das limitações e possibilidades de cunho pessoal e coletivo existentes. A expectativa é de que essa estratégia interacional possa contribuir para o aperfeiçoamento da capacidade do professor em dialogar com seus pares e a coordenação e, também, de lidar com emoções e prioridades, a ponto de efetivar o processo pedagógico, conforme planejado, e de torná-lo gratificante para todas as pessoas envolvidas.

Houve consenso em que a AIP, para atingir seus objetivos e finalidades, deve calcar-se nos componentes do cuidado que promovam o aprimoramento humano, dirigidos à integração de componentes de razão-sensibilidade e liberdade-limite, mediados pela reflexão crítica e o caráter dialético, inerente à realidade complexa e mutante.

Também foi identificada a necessidade de o professor ficar mais atento aos princípios prescritos que dizem respeito à aprendizagem progressiva e à importância de gerar, no aluno, a percepção de ser sujeito do processo de produção do conhecimento e sentir prazer com esse trabalho. Nesse sentido, foi apontado o papel relevante dos professores dos primeiros semestres do curso para o sucesso das propostas pedagógicas e, também, para a manutenção dos alunos no curso e na universidade. Um dos encaminhamentos desafia os docentes ao desenvolvimento de estratégias que mobilizem o aluno à participação efetiva. Para tanto, precisam provocar a sua inserção imediata nos processos pedagógicos e nos contextos da saúde e da profissão, e respeitar sua capacidade de atendimento às demandas acadêmicas, de maneira a estimularem seu envolvimento e prevenirem situações que possam provocar riscos de estresse e evasão.

Identificou-se que a AIP possibilita desenvolver o potencial do aluno para atender a uma variedade de exigências de conteúdos teóricos e metodológicos como uma unidade complexa. A visão multidimensional da saúde e a bagagem existencial e de cidadania dos participantes, quando presentes no processo, fortalecem esse aspecto e evidenciam que os questionamentos e as buscas por respostas, junto à população, a seus pares, a seus professores e outros profissionais, devem ser mediados por interações de caráter ético e estético.

Com base nas teses de Briceño-León (1996), percebe-se a AIP também como estratégia pedagógica para reforçar a confiança das pessoas em si mesmas e fomentar a responsabilidade individual e a cooperação coletiva na formação acadêmica.

Mediante a discussão da avaliação, alguns professores foram levados a refletir criticamente sobre o seu perfil de docente universitário e a ressignificar conceitos sobre pesquisa na graduação e práticas pedagógicas. Perceberam que certas práticas que desenvolviam não somente inibiam a participação do aluno, mas também provocavam estresse desnecessário. Exemplo disso é a quantidade elevada de trabalhos e de provas exigida no semestre, resquícios do modelo fragmentado e quantitativo que costuma gerar sobrecarga de trabalho, insatisfação e pouca aprendizagem.

A estratégia AIP atendeu à expectativa dos idealizadores de caracterizá-la como uma metodologia de ensino-aprendizagem de abordagem construtivista. Nesse modelo, segundo Grossi (1995), do ponto 
de vista do ensinante, a prática pedagógica deve propiciar ao aluno o embate com problemas instigantes que suscitem a necessidade de resolvê-los por meio de saídas inteligentes, que devem ser superadas gradativamente pelo próprio sujeito da aprendizagem. $\mathrm{E}$, ainda, conforme a autora, embebidos na dimensão do social, essa prática deve promover conquistas pessoais que instrumentalizem os alunos para a resolução de problemas existenciais tanto na esfera profissional quanto na esfera pessoal.

Finalmente, essa modalidade de ensino foi considerada apropriada para outros espaços acadêmicos que tenham a mesma expectativa, condicionada a modificações relacionadas à essência da profissão, ao PPC do curso e aos processos reflexivos e criativos que mediarão o trabalho coletivo naquele contexto.

\section{Síntese final}

A sistematização da AIP mostra um processo de trabalho fundado em práticas pedagógicas orientadas por referencial teórico-metodológico próprio, sintonizado com o PPC e o contexto maior em que se insere. Partindo da proposta inicial, a AIP foi sendo construída e validada, pelos participantes, no decorrer dos processos de trabalho, e reconhecida como um método original.

Nesse processo, alunos aprendem a construir o seu próprio conhecimento em nível de complexidade crescente, e professores que ensinam também aprendem para além do conteúdo que lhes cabe ministrar - ampliam sua visão como profissionais da educação superior e da saúde e, também, como cidadãos.

A proposta, firmada pela sistematização de estratégias pedagógicas, representa processos de ensinaraprender a fazer pesquisa a partir da aplicação e recriação de conhecimentos e do exercício da associação sabedoria, criatividade e reflexão crítica. Conduzida por situações-problema de complexidades e de contextos variados, é mediada por processos de análise-reflexão-síntese individuais e coletivos e por componentes do cuidado humano que promovem o aperfeiçoamento das interações pessoais e profissionais.

A perspectiva de aprimoramento de teorias e práticas sobre necessidades humanas, cuidado integral e processos de trabalho para promoção e prevenção de agravos à saúde em diferentes contextos, exige o desenvolvimento de conhecimentos para além daqueles previstos no semestre. Esse aspecto leva alunos e professores - sobretudo estes - à busca em fontes diversas, ao aperfeiçoamento do poder de reflexão e ao incremento de atitudes construtivistas.

O estudo mostrou que o ensino da pesquisa, quando inserido em todos os semestres da graduação, desenvolvido de maneira interdisciplinar, participante, construtivista e solidária, promove o empoderamento gradativo do aluno para desenvolver suas competências e habilidades. Esse processo gera desafios constantes para o professor, o que lhe possibilita maior empoderamento como educador, pesquisador e profissional de sua área.

A estratégia de avaliação da AIP, por envolver a discussão coletiva dos processos e resultados, fortalece os princípios da proposta e constitui mais um recurso para integração dos participantes, capacitação em pesquisa e aperfeiçoamento pessoal e profissional de maneira geral.

Ensinar-aprender conteúdos pesquisando em livros, banco de dados e contextos sociais, e a discutir dialogando com seus pares e mestres, sintoniza-se com ideias de Ortega e Gasset apud Droguett (2002), Freire (2000, 1983), D’Ambrósio (1997) e Grossi (1995), no que se refere à importância do desenvolvimento de métodos pedagógicos que transcendam àqueles que apenas reproduzem conhecimentos.

Seus princípios e estratégias possibilitam o aperfeiçoamento das habilidades e competências de discentes e docentes para identificar situações-problema no cotidiano das práticas e, também, para criar e aplicar conhecimentos básicos e tecnológicos que respondam de forma mais coerente às demandas da profissão e da sociedade. E, ainda, possibilitam, pelo seu caráter cooperativo e seus aspectos éticos e estéticos, tornar a experiência da educação formal saudável e prazerosa, tal como apregoado nas obras de Rubem Alves $(2008,2001)$.

Embora essa modalidade possa gerar condições de estresse, promove, mesmo nas situações de conflito e grandes dificuldades, o aperfeiçoamento das interações docente-docente, discente-docente e 
discente-discente, em razão de seus princípios e referenciais valorizarem o caráter dialógico e de cuidado consigo e com o outro. Tal consideração é evidenciada nos estudos de Ribeiro et al. (2010) e Silvério et al. (2010), que tratam de repercussões do processo de ensino-aprendizagem na qualidade de vida e saúde de alunos e professores.

Essa tecnologia social apresenta potencial, também, para incrementar objetivos e diretrizes da educação que, transformando o ser humano, transforma a sociedade, mas com a preocupação de se constituir em prática social sustentável - em todos os sentidos que essa expressão possa representar no universo da produção e disseminação de conhecimentos científicos e saberes tradicionais.

Ainda que a proposta esteja restrita a um microcontexto acadêmico da área da saúde, entende-se que essa modalidade de ensino, sob um olhar sistêmico, constitui-se subsídio para ampliação da consciência e participação social da universidade. Sob vários aspectos, a proposta apresenta ressonância com a incitação que Boaventura Santos faz à universidade do Século XXI (2005), no que tange à responsabilidade social e política, fundada por princípios democráticos e emancipatórios.

Ao considerar o contexto em que foi construído esse método, à luz de concepções de Chauí (2003), relacionadas às mudanças ocorridas na universidade brasileira que ferem seu caráter de "universalidade", é possível sonhar que práticas pedagógicas dessa natureza, em universidades cujo perfil é predominantemente de "organização social", possam contribuir para a promoção, ou o resgate, de atributos que confiram ou restituam o caráter de "instituição social" da universidade.

Particularmente, citando Soubhia, Garanhani, Dessunti (2007, p.183), ressalta-se que

a realização deste estudo possibilitou-nos compreender que a competência se constitui, por ora, a nossa grande utopia, mas a caminhada está iniciada e com o trajeto sinalizado.

Restam-nos, ainda, novos olhares para o fenômeno e outras avaliações do processo de ensino e aprendizagem sobre a pesquisa.

Sugere-se a realização de estudos semelhantes em outros contextos, que possam incrementar o desenvolvimento - ou mesmo validar pela sistematização - de metodologias voltadas ao ensino sistemático da pesquisa na graduação que, além de promoverem a inclusão de alunos nessa aprendizagem e sua autonomia progressiva na abordagem da realidade, também contribuam para aprimorar a profissão e o diálogo entre professores, gestores e a sociedade. Nesse âmbito, a expectativa é incrementar o aperfeiçoamento docente contínuo, a produção científica da universidade e a sua maior inserção social.

\section{Colaboradores}

Zuleica Maria Patrício, Maria Regina Silvério e Ivete Maria Ribeiro trabalharam em todo o processo da pesquisa, na construção e na redação final do manuscrito; Janete Elza Felisbino participou da concepção da pesquisa, coleta de dados e redação inicial do manuscrito; Ingrid May Brodbeck, Greice Wessler Medeiros Martins, Gilmara Medeiros Vieira da Silva, Adriana Elias dos Reis, Ana Maria Henrique Martins Costa, Elvis Diene Bardini e Vera Maria Antunes da Fonseca Pinto participaram da concepção inicial da pesquisa e da coleta dos dados. 


\section{Referências}

ALVES, R. Entre a ciência e a sapiência: o dilema da educação. 19.ed. São Paulo: Loyola, 2008.

Conversas com quem gosta de ensinar: qualidade total na educação. 3.ed. São Paulo: Papirus, 2001.

ÁVILA, V.F. A pesquisa na dinâmica e na essência da universidade: ensaio para estudantes, professores e outros profissionais. Campo Grande: UFMS, 1995.

BARDIN, L. Análise de conteúdo. Lisboa: Edições 70, 1977.

BARNECHEA, M.; GONZÁLEZ, E.; MORGAN, M.L. La sistematizacion como produccion de conocimientos. Taller Permanente de Sistematización-CEAAL - Perú. Lima, 1994. Disponível em: <http://preval.org/documentos/00508.pdf>. Acesso em: 7 mar. 2009.

BOTERO, L.D.R. La sistematización de practicas. Bogotá: Portal OEI, 2001.

BOTOMÉ, S.P. Pesquisa alienada e ensino alienante: o equívoco da extensão universitária. Petrópolis: Vozes/UFCar/UCS, 1996.

BRICEÑO-LEÓN, R. Siete tesis sobre la educación sanitaria para la participación comunitaria. Cad. Saude Publica, v.1, n.12, p.7-17, 1996.

CHAUÍ, M. A Universidade pública sob nova perspectiva. Rev. Bras. Educ., n.24, p.5-15, 2003.

COLLIÉRE, M.F. Invisible care and invisible woman as health care-providers.

Int. J. Nurs. Stud., v.23, n.2, p.95-112, 1986.

COMERLATTO, D. Um olhar sobre o ensino da pesquisa: a experiência dos cursos de graduação em serviço social da região sul. 2008. Tese (Doutorado) - Faculdade de Serviço Social, Pontifícia Universidade Católica do Rio Grande do Sul, Porto Alegre. 2008.

D'AMBRÓSIO, U. A era da consciência: aula inaugural do primeiro curso de pósgraduação em ciências e valores humanos no Brasil. São Paulo: Fundação Petrópolis, 1997.

DEMO, P. Pesquisa: princípio científico e educativo. São Paulo: Cortez, 2006.

DROGUETT, J.G. Ortega y Gasset: uma crítica da razão pedagógica. Petrópolis: Vozes, 2002.

FÓRUM NACIONAL DE PRÓ-REITORES DE GRADUAÇÃO DAS UNIVERSIDADES BRASILEIRAS. Ensino de graduação: políticas, diretrizes e interfaces com a pesquisa e a extensão: Carta de Recife (2002). Disponível em: <www.prograd.ufu.br/forgrad2004/ pg_internas/docs/docs_2002_2003/carta_de_recife_introduçao_xv_forgrad.rtf $>$. Acesso em: 8 mar. 2009.

FREIRE, P. Pedagogia da autonomia: saberes necessários à prática educativa. Rio de Janeiro: Paz e Terra, 2000.

Educação e mudança. Rio de Janeiro: Paz e Terra, 1983.

GHISO, A. Sistematización de experiencias en Educación Popular. In: LOS CONTEXTOS ACTUALES DE LA EDUCACIÓN POPULAR, 2001, Medellín. Memorias... Medellín, 2001. p.71-88.

GROSSI, E.P. O passo no escuro do aprender: ato solidário de audácia, entrega e prazer. In:_. (Org.). Celebração do conhecimento na aprendizagem. Porto Alegre: Sulina, 1995. p.11-24.

HORTA, W.A. O processo de enfermagem. São Paulo: EPU/Edusp, 1979. 
JARA, O.H. Para sistematizar experiências. João Pessoa: Ed. UFPB, 1996.

LAFFIN, M. A pesquisa nos cursos de ciências contábeis. Florianópolis: CSE/UFSC. Disponível em: <http://www.Cse.Ufsc.Br/ Cad/Revista.Php3\#/html>. Acesso em: 10 dez. 2008.

LEININGER, M. Care the essence of nursing and health. Thorofare: John Wiley \& Sons, 1984.

MINAYO, M.C.S. O desafio do conhecimento: pesquisa qualitativa em saúde. São Paulo: Hucitec, 2004.

MOOR, A.M. Gestão de ensino na Universidade Pública no século XXI: o que é isso? Palestra proferida na PUC/RS, Brasil. 2003. Disponível em: <http:// minerva.ufpel.edu.br/ anne.moor/gestao_academica.htm>. Acesso em: 7 mar. 2009

MORATO, C.T. A função formadora da pesquisa nos cursos de graduação em música da Universidade Federal de Uberlândia (UFU)-MG. Ouvirouver, v.1, n.1, p. 87-94, 2005.

NÓBREGA-THERRIEN, S.M.; THERRIEN, J. Ensino e pesquisa nos cursos de graduação em educação e saúde: apontamentos sobre a prática e análise dessa relação. Rev. Faced, v.1, n.10, p.279-93, 2006.

PATRÍCIO, Z. M. et al. O processo participante de ensinar-aprender pesquisa qualitativa: transformando atores e contextos In: CONFERÊNCIA INTERNACIONAL DO BRASIL DE PESQUISA QUALITATIVA - CIBRAPEQ, 1., 2004, Taubaté. Anais... São Paulo: Tec Art, 2004. p.668-77.

PATRÍCIO, Z.M. Métodos qualitativos de pesquisa e de educação participante como mediadores na construção da qualidade de vida: novos paradigmas, outros desafios e compromissos sociais. Texto Contexto Enferm., v.3, n.8, p.53-67, 2000.

Ser saudável na felicidade-prazer: Uma abordagem ética e estética pelo cuidado holístico-ecológico. Pelotas: UFPel, 1995.

. Nem talco nem diamante: a riqueza de um processo de ensino-aprendizagem participante na área da sexualidade-adolescência. Texto Contexto Enferm., v.2, n.3, p.93-109, 1994.

A prática do cuidar-cuidado à família da adolescente grávida através de um referencial de enfoque sócio-cultural. 1990. Dissertação (Mestrado) - Programa de Pós-Graduação em Enfermagem, Universidade Federal de Santa Catarina, Florianópolis. 1990.

RIBEIRO, I.M. et al. Repercussões do processo ensino-aprendizagem na qualidade de vida-saúde de acadêmicos: entre possibilidades e limitações. REME. Rev. Mineira Enferm., v.14, n.1, p.96-102, 2010.

ROSSI, M.F.P.; RIBEIRO, M.P.; TEODÓSIO, A.S.S. O trabalho integrado como iniciação à pesquisa na graduação em Administração. Disponível em: <http://www.pucmg.br/ seminarioprograd/iv_seminario/pdfs/administracao_betim.pdf $>$. Acesso em: $3 \mathrm{dez}$. 2008.

SANTOS, B. A universidade do século XXI: para uma reforma democrática e emancipatória da universidade. São Paulo: Cortez, 2005.

SILVÉRIO, M.R. et al. O ensino na área da saúde e suas repercussões na qualidade de vida docente. Rev. Bras. Educ. Med., v.34, n.1, p.65-73, 2010.

SOUBHIA, Z.; GARANHANI, M.L.; DESSUNTI, E.M. O significado de aprender a pesquisar durante a graduação. Rev. Bras. Enferm., v.60, n.2, p.178-83, 2007.

ZATTI, V. Autonomia e educação em Immanuel Kant e Paulo Freire/Vicente. Porto Alegre: EDIPUCRS, 2007. 
PATRÍCIO, Z.M. et al. Sistematización de estrategias de enseñanza-aprendizaje de la pesquisa en la graduación. Interface - Comunic., Saude, Educ., v.15, n.39, p.1159-72, out./dez. 2011.

Este estudio analiza la sistematización de prácticas pedagógicas de enseñanza y aprendizaje de la pesquisa en el cotidiano de las asignaturas de un curso de graduación del área de la salud. Los datos provienen de documentos concernientes a las actividades pedagógicas desarrolladas y analizados por la técnica de análisis de contenido, siguiendo categorías del referencial de sistematización de prácticas sociales adoptado: delimitación del objeto; tiempo y contexto; objetivos y finalidades; referenciales utilizados; contenido de las prácticas y estrategias utilizadas; dinámica de las actividades y sentimientos creados; resultados; conclusiones y propuestas de encaminamientos. Los resultados presentan un método de enseñanza y aprendizaje de la pesquisa creado en colectivo, constituido por un referencial teórico-metodológico propio que orienta, en todas las asignaturas, el desarrollo de estrategias para que se construyan conocimientos a nivel de complejidad creciente, basados en situaciones-problema de la salud y datos cualitativos y cuantitativos de diferentes frentes y contextos socio-ambientales.

Palabras clave: Enseñanza de pesquisa. Educación superior. Estrategias de enseñanza-aprendizaje. Sistematización de prácticas. 